\title{
Production and judgment of "humor" by schizophrenics and college students
}

\author{
PETER L. DERKS, HARRY M. LEICHTMAN, and PATRICK J. CARROLL \\ The College of William and Mary, Williamsburg, Virginia 23185
}

\begin{abstract}
Captions for stills from old movies were produced by schizophrenics and college students under instructions to be funny. Subsets of these captions were selected as schizophrenic, collegiate, or ambiguous as well as relatively funny or not funny. Another group of schizophrenics and college students judged these captions for their schizophrenia and humor. Schizophrenics did not make up funnier captions, did not do better in diagnosing schizophrenic captions, and all subjects judged that schizophrenia and humor did not go together.
\end{abstract}

Most conceptions of humor give the surprising or the incongruous a central role (Keith-Spiegel, 1972). Pollio and Mers (1974), however, found that the funny lines in the routines of comedians are more, rather than less, predictable. Another population that can be characterized by unusual behavior, whether through lower intelligence, concreteness, or over-inclusive thinking is composed of schizophrenics (Payne, 1973). Schizophrenic language, on the other hand, has been described as not too different from normal speech (Brown, 1973). In fact, normals have been comitted to psychiatric hospitals, and no one discovered that they were not real patients, except the patients themselves (Rosenhan, 1973).

The following study was an examination of two hypotheses suggested by these observations. First, schizophrenics might be funnier than normals. Second, schizophrenics might be better judges of what is schizophrenic humor. The main interest in this research, however, was humor rather than schizophrenia. The college student population with which the schizophrenics were compared differed in too many ways other than diagnosed schizophrenia to be considered a true control, and no attempt was made to differentiate among various classifications of schizophrenics.

\section{METHOD}

\section{Material}

Six still photographs from old movies were selected from Franklin (1959) by the five funniest participants in an earlier pilot study. The pictures were chosen for their potential to elicit "funny captions," a caption that would make the picture more amusing. Sixteen college students from William and Mary and 16 diagnosed schizophrenics from Eastern State Hospital volunteered to serve in the original sample. Both groups contained eight males and eight females.

These humor sources were instructed to make up as many

Requests for reprints, the contents of the short form of the "humor" test. and further information should be sent to Peter L. Derks. Department of Psychology. College of William and Mary. W'illiamsburg. Virginia 23185. captions as they could for each picture. The captions were to be "funny, something to make someone else laugh, but don't be too critical of yourself." A total of 594 captions were produced, about 3.9 per individual per picture by the college group and about 2.3 captions per person per picture by the schizophrenics.

Eleven students from an advanced psychology class diagnosed these captions to be "schizophrenic" or "collegiate." The hit rate for schizophrenic was $53 \%$, and the false alarm rate, college called schizophrenic, was $36 \%$. Sixteen other students were paid $\$ 1.60$ an hour to rate the humor of the captions on a scale from 0 to 10 . A caption "not funny at all" was rated 0 and "very funny," 10. Either because they were paid and took the task too seriously, or because there were so many captions, or because the captions were not very funny, the captions were not rated very funny over all. The schizophrenic captions averaged 1.24 , and the college student captions averaged 1.98, $\mathrm{t}(30)=4.77$, $p<.001$. The first hypothesis about the higher quality of schizophrenic humor was at least partly disconfirmed.

To find out how schizophrenics would judge the humor and to obtain a more sensitive measure on college students, a short form of 72 captions was constructed from the original sample. These captions were selected to include a balance of caption sources (schizophrenic or college students); diagnoses by the 11 students (schizophrenic to all, college student to all, and ambiguous-a caption called schizophrenic by five or six of the college diagnosers); and the humor ratings of the 16 students (relatively "good" was an average rating of 2.8 or over, "poor" was an average rating below 1.5 , and "fair" was an average rating between 2.8 and 1.5). The captions were equally divided by source, 36 from schizophrenics and 36 from college students, and each picture had 12 captions in the short form. The variability of rating and diagnosis, however, prevented the other categories from being equal. There were 10 captions for schizophrenics that had been diagnosed schizophrenic, 17 that were ambiguous, and 9 called college student captions. For the college student captions, 7 were chosen that had been diagnosed schizophrenic, 16 that were ambiguous, and 13 that were called college student captions. Only 11 captions qualified for a good rating, and none of these had been diagnosed schizophrenic. Subsequently, it was possible to combine these with the 29 fair captions, so that 40 better-than-average captions could be compared with 32 poor captions.

\section{Subjects}

To judge this short form, 20 different schizophrenics were chosen from the same population as before. Whenever possible, these judges were of college age and as intelligent as possible, in an effort to match them with the college population. Their average age was 23 years, and six of them had been to college. The oldest was 31 years, and all had at least reached the junior 
Table 1

Percentage of Captions Diagnosed Schizophrenic in Each Category of Caption, Source, Prior Diagnosis, and Present Judge

\begin{tabular}{|c|c|c|c|c|c|c|c|}
\hline & & & Coll & & & Schiz & \\
\hline Prior D & gnosis & Coll & Ambig & Schiz & Coll & Ambig & Schiz \\
\hline & Coll & 13.8 & 40.1 & 57.4 & 10.5 & 41.5 & 82.0 \\
\hline Juage & Schiz & 33.5 & 44.4 & 60.7 & 42.8 & 47.6 & 53.0 \\
\hline
\end{tabular}

year in high school. Twenty new college students were chosen from the same college population. Both groups contained 10 males and 10 females.

\section{Procedure}

Each judge was tested individually on all six pictures and their 12 captions. The pictures and captions were presented in random orders. The judges were asked to diagnose who had made up the caption, someone at the "hospital" (Eastern State) or someone at the "college" (William and Mary). They were also asked to rate the captions on a scale from 0 to 10 , with 0 "not funny at all" and 10 "very funny."

Since each category of prior diagnosis and prior humor rating did not receive equal representation, it was necessary to average the humor ratings and take percentages for the diagnosis. Each category was compared by these averages or percentages rather than absolute scores. Consequently, there are problems in the interpretation of the results due to limited sampling of some condition. For example, there were no good captions by schizophrenics. Therefore, the conclusions of this study are stated in their weakest form.

\section{RESULTS AND DISCUSSION}

\section{Diagnosis}

As there was no main effect for sex of judge in the initial analysis, $F(1,36)=.10$, the male-female dimension was disregarded in the final analysis. There were interactions that resulted from the relative insensitivity of female schizophrenics to the cues used by the other groups, but, given the size of these groups, these differences were more probably a result of sampling than characteristics of female schizophrenics in general. Therefore, Table 1 gives the percentage of the captions diagnosed schizophrenic in the various categories by all college students and all schizophrenics.

In general, schizophrenic judges called more captions schizophrenic, $47.0 \%$ to $40.8 \%, F(1,38)=7.76, p<.01$. Furthermore, schizophrenic captions received a higher percentage of schizophrenic diagnoses over all, $46.2 \%$ to $41.6 \%, F(1,38)=5.62, p<.025$. The interaction, however, was not significant, $F(1,38)=2.16, p>.10$. Without reference to the diagnoses of the college students, schizophrenics were not more sensitive to whatever evidence of schizophrenia might have been in the captions.

The cues that had influenced the diagnoses of the first sample of college students also influenced the present judges. Although the differences were not as extreme as for the selection condition, captions originally diagnosed schizophrenic were diagnosed schizophrenic more often than ambiguous captions, which were diag- nosed schizophrenic more often than captions that previously had been diagnosed collegiate, $F(2,76)=75.41$, $p<.001$. Furthermore, there was an interaction between prior diagnosis and present judge, $\mathrm{F}(2,76)=19.64, \mathrm{p}<.001$, and these variables produced a triple interaction with the source of the caption, $F(2,76)=15.70, p<.001$. Table 1 shows that these interactions are due to the greater sensitivity of the college students to the cues used by the first group of students to diagnose the captions. Schizophrenics did not do a better job of diagnosing these captions than did the college students.

\section{Humor Ratings}

Again there was no main effect of sex of rater, $\mathrm{F}(1,36)=.01$, so Table 2 presents the average humor ratings by caption category comparing college and schizophrenic judges averaged over males and females. The captions on this short form were generally rated higher than in the original testing. The good captions received a mean rating of 4.56 , the fair, 4.04 , and the poor, 3.25. Given the short supply of good captions and the relatively high ratings of the fair cpations, these two categories were combined for final analysis as indicated by Table 2. Good and fair captions were rated significantly funnier than poor captions $F(1,38)=23.49$, $\mathrm{p}<.001$, and schizophrenics rated all captions an average of about one unit higher than they were rated by college students, $\mathrm{F}(1,38)=8.24, \mathrm{p}<.001$.

As for the source of the caption in this preselected test, there was no significant difference between the humor ratings on captions from college students and schizophrenics, $F(1,38)=.75$. With the captions preselected as good or poor, there was no emergence of something funny that hadn't been recognized before. There was, however, an interaction between the judge's diagnosis and humor rating, $F(1,38)=31.52, p<.001$. A good caption was rated an average 1.66 units lower when it was called schizophrenic, and a poor caption was rated an average of 1.26 units lower, a significant Quality by Diagnosis interaction, $F(1,38)=4.78$, $p<.025$. There were, however, no significant interactions with the judges; judge-quality, $\mathrm{F}(1,38)=.92 ;$ judge-source, $\quad \mathrm{F}(1,38)=1.16 ;$ and judge-quality-source, $F(1,38)=.00$.

Table 2

Humor Ratings of Captions by Prior Quality, Source, Present Diagnosis, and Present Judge

\begin{tabular}{|c|c|c|c|c|}
\hline \multirow{2}{*}{$\frac{\text { Source }}{\text { Present Diagnosis }}$} & \multicolumn{2}{|c|}{ Coll } & \multicolumn{2}{|c|}{ Schiz } \\
\hline & Coll & Schiz & Coll & Schiz \\
\hline \multirow{4}{*}{ Judge } & \multicolumn{4}{|c|}{ Good and Fair Quality } \\
\hline & 4.25 & 2.64 & 3.89 & 2.45 \\
\hline & 5.24 & 3.56 & 5.38 & 3.49 \\
\hline & \multicolumn{4}{|c|}{ Poor Quality } \\
\hline Coll & 3.42 & 2.50 & 3.31 & 2.19 \\
\hline Schiz & 4.58 & 2.89 & 4.58 & 3.18 \\
\hline
\end{tabular}


Not only did college students rate schizophrenics less funny than other college students, schizophrenics rated schizophrenics less funny themselves. From this study, it is not possible to say whether finding something less funny made it schizophrenic or deciding it was schizophrenic reduced its humor. It is clear, however, that "crazyness" is not an essential part of amusement.

\section{REFERENCES}

Brown, R. Schizophrenia, language, and reality. American Psychologist, 1973, 28, 395-403.

Franklin, J. Classics of the silent screen, New York: Citadel, 1959.
Keith-Spiegel, P. Early conceptions of humor: Varieties and issues. In H. H. Goldstein, \& P. E. McGhee (Eds.), The psychology of humor. New York: Academic Press, 1972.

PAYNe, R. W. Cognitive abnormalities. In H. J. Eysenck (Ed.), Handbook of abnormal psychology (2nd ed.). London: Pitman Medical, 1973.

Pollio, H. R., \& Mers, R. W. Predictability and the appreciation of comedy. The Bulletin of the Psychonomic Society, 1974, 4. $229-232$.

Rosenhan, D. L. On being sane in insane places. Science, 1973, 179. 250-258.

(Received for publication June 11, 1975.) 